\title{
CD-ROM: Expanding and shrinking resource based learning
}

\author{
John G Hedberg \\ University of New South Wales
}

Over the past few years there has been a rapid development in the integration and sophistication of technologies that can be used for learning. One of the more interesting delivery technologies is the Compact Disk-Read Only Memory (CD-ROM)(1), which can provide for the individual learner, a vast range of resources. As the learner sits at his or her personal work station, retrieval software can allow access to encyclopedias, research databases, sound libraries, newspaper clippings, picture collections, photographic collections, software libraries, and computer-based instruction including animated sequences. Major publishers are releasing important works through this medium and are thus providing a unique resource for the individual learner. Already the availability of research collections such as the ERIC database has enabled reduced search costs and faster turnaround for investigators who wish to browse through citations and their abstracts. The bibliography which follows this paper was produced using this technology - a CD-ROM of the ERIC database.

Each CD-ROM provides around 550 megabytes of storage which is more than 650 small floppy disks. This means than the storage space required for large information collections has been drastically reduced over its equivalent print or even its floppy disk format. Most of the first commercial CD-ROMs were databases which could be easily converted from mainframe magnetic storage to CD-ROM. Early titles included the complete ERIC database, the Medical database MEDLINE, and many other specialized databases of research literature, toxic chemicals, corporate and industry research reports, etc. More recently the titles (2) include PD-ROM (the public domain software collected by the Berkeley Macintosh Users Group which includes several hundred megabytes of software, shareware, clip art and technical information for the Macintosh), Xiphias Time Table of History (a hypermedia journey which links thousands of different stories 
about science and technological achievements), The MacroMind CD-ROM (a collection of clip sounds, art movies and animation for use in producing your own desktop video programs), and disks which allow searches of newspaper articles on specific topics. In the last case, it is possible not only to view the topics discussed but also to read the articles and print out copies of the material.

CD-ROM offers a range of learning possibilities which have been largely ignored in the past because of the cost and complexity of providing resources. Learners have often been provided with the specific information rather than being given a general question and required to develop their own search and problem formulation strategy. CD-ROM technology and its later variants (3) pose some interesting challenges for the development of new and alternative teaching/learning strategies. Not only are vast amounts of information available but the learner must know how it can be retrieved, and what are appropriate strategies for searching digitized information. Visual browsing, which was possible with the book, is no longer an option. Instead, the learner must become familiar with scanning through screens of information-digitized encyclopedias. The challenge to developing new learner skills must be confronted by both teacher and instructional designer. Many writers have argued that the information technologies can provide a variety of supplanting skills for the learner; helping the learner to understand a concept more efficiently and effectively (Englebart, 1988). With CD-ROM as an additional resource, the personal computer can be an extension of the individual's ability to think and manipulate the world around them.

Learning resources have been expanded by the increased density of storage and the interest with which traditional publishers have embraced these new non-print delivery technologies. The number of CD-ROM titles and the ease of producing and distributing copies poses interesting challenges for state education departments. Is a satellite linkup necessary for distance education students when each student could have his or her own copy of the resources and a teleconference quickly convened to cover the tough points! What would it cost to provide multiple copies of this new resource in media learning centres in schools? And, would this be as effective as printed resources.

The miniaturization of information and knowledge collections, together with the increased ability to use the personal computer as a visual and aural presentation device for motion and photographic sequences, has produced a more integrated view of the information and communications technologies. The use of CD-ROM storage and retrieval technology takes the learner one step closer to an integrated learning system. Four years ago Nicholas Negroponte the Director of the Media Lab at the Massachusetts Institute of Technology presented the following diagram as a forecast of what might happen in the communications and computer industries. The 
result today with $\mathrm{CD}-\mathrm{ROM}$ and with inventive applications software becoming available has been to create an integrated work platform on which a variety of visual and aural experiences can be presented to and investigated by the user.

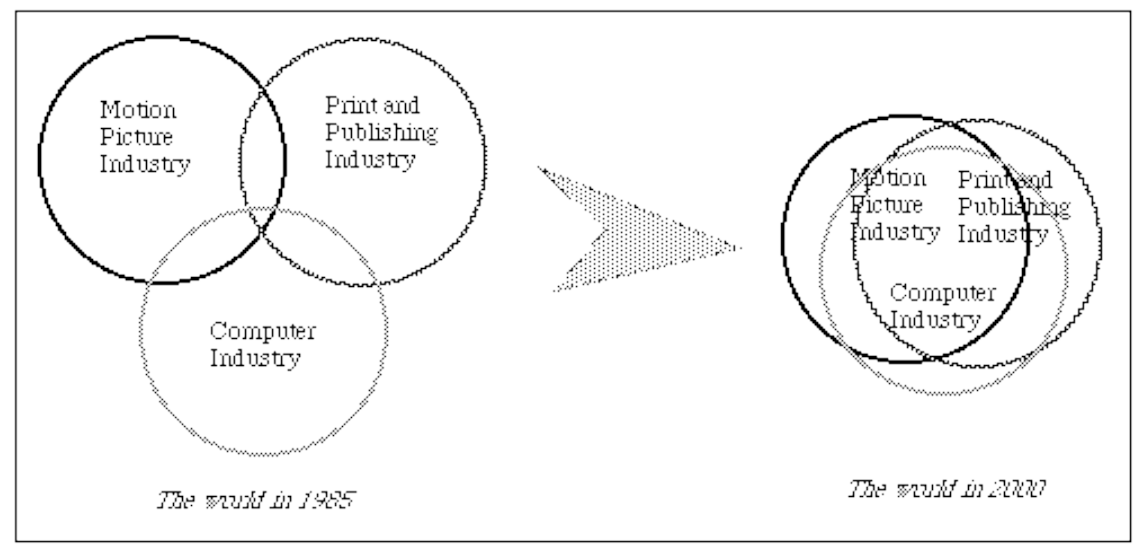

Figure 1: Converging technology industries (Negroponte, in Brand, 1988)

\section{Hypermedia: Creating new information links}

The provision of large quantities of resources has created problems in demonstrating the methods for finding and linking ideas and facts together. Hypercard and other hypermedia products allow links between elements of information in ways not previously available to the teacher. In a recent work by David Jonassen (1989), the multi-links between information were presented in a regular print medium with suggestions about the page to turn to for further information (although I feel this presentation was not as successful as on computer screen). In a hypermedia environment many links can be made between elements in a information database (with elements which might include any visual, aural, numerical or verbal information). When linked with CD-ROM or other computer-controlled media storage devices, a multimedia workstation is produced. The resulting combination throws out challenges for libraries, media departments, computer departments and the hundreds of separate areas in the education enterprise which have not always talked to each other. They can no longer claim that they are operating with different technologies or media.

CD-ROM can be seen as a catalyst which will bring together all the providers, the keepers, the organisers, the presenters and the users of information and the knowledge derived from it (O'Connor, 1986). The economics of producing each disk, together the variety of representational forms and quantity of information it can contain, will mean that the 
diverse groups will need to start talking. Ignoring the challenge and the potential could mean that some people currently calling themselves educational technologists (in the variety of guises - media producer, instructional designer, computer software author, etc.) could require retraining for the new multimedia designer positions to become available. The real gain will be for learners, if they can gain access to workstations using the technology.

As educators, we are faced with increasingly complex decisions in the area of educational technology. In an ideal world, institutions with unlimited funds would pick and choose among technologies to create a state-of-theart, customized instructional environment. Outmoded equipment would be replaced as quickly as new advanced and refined versions appeared on the market. In the real world, however, hard choices must be made about deciding how to invest limited resources - money, personnel, and time, but the CD-ROM technology and the ability to integrate a rich source of learning experiences must be considered as a cost effective and exciting development.

\section{Notes}

1. CD-ROM stands for Compact Disc-Read Only Memory. It is similar to the common audio compact disc and contains approximately 550 megabytes of storage on the small silver disc. Information can be stored as images $(15,000$ images), text (150,000 pages), or sound (30 minutes). CD-ROM offers the potential to provide massive amounts of information to a large number of individuals at a relatively low price. It is the growing and preferred method for distributing public databases such as ERIC, Social Sciences Index, Science Index, and many more.

2. Many of these titles are available from Firmware Design, P.O. Box 290, Blaxland NSW 2774, Australia.

3. Other variants include CD-I and DV-I. CD-I stands for Compact Disc Interactive. This technology is similar to the CD-ROM technology except that the disc is designed to show restricted motion video (digitally encoded), audio and other digital information such as programs and databases. Each level and type of information will require different amounts of storage space on the disc; therefore, careful design of the disc is essential. For instance, the audio can be specified to be at speech level, LP music quality level, or CD-A quality level. The video is digitized and if full motion is used, it is limited to 60 minutes on a quarter of the screen. The technology is in a beta test version and should be ready for mass release during 1989. CD-I players are estimated to cost about $\$ 1100$, with discs available for $\$ 35$. Applications are intended for home and domestic use.

DV-I stands for Digital Video Interactive. This technology is similar to the CDROM technology except that the disc is designed to show full screen full motion video (compressed digitally encoded) as well as other digital information such as programs and databases. The all-digital system is interactive, allowing user control of foreground video object, text, dynamic 
graphics, and audio. The major advantage of DV-I over other optical media is the large amount of motion (74 minutes) stored on the compact disc. This technology requires a special compression/decompression technique. Using large mainframe computers, the digital video and audio data are compressed so that fewer bits are required for storage. Each time the DV-I is played, the compressed data must be decompressed in real time. This is accomplished by two special computer chips. The cost of this system is estimated to be approximately $\$ 10,000$. The initial market for DV-I is the military and industry, where large amounts of high quality video are needed for realism in training simulations. The technology has been under development for the past two years, and experts predict that DV-I prices should be affordable to consumers in early 1990.

\section{References}

Brand, S. (1988). The media lab. New York: Penguin.

Engelbart, D.C. (1988). The augmentation system framework. In S. Ambron, \& K. Hooper, (Eds.). Interactive Multimedia: Visions of multimedia for developers, educators, and information providers. Redmond, WA: Microsoft Press.

Jonassen, D. (1989). Hypertext/Hypermedia. Englewood Cliffs, NJ: Educational Technology Publications.

O'Connor, M. A. (1986). Education and CD-ROM. Optical Information Systems, 6(4), 329-31.

\section{Bibliography on CD-ROM}

This bibliography is based on a search of the ERIC database using Silver CDROM with Silver Platter retrieval software on a MS-DOS system. Search dates from 1981 to December 1988. Keywords used were: CD-ROM (105 hits), and CD INTERACTIVE (5 hits).

Bardes, D'Ellen (1986). Attention Novices: Friendly Intro to Shiny Disks. Library Software Review, 5(4), 241-45. (EJ342850)

Provides an overview of how optical storage technologies - videodisk, Write-Once disks, and CD-ROM CD-I disks are built into and controlled via DEC, Apple, Atari, Amiga, and IBM PC compatible microcomputers. Several available products are noted and a list of producers is included. (EM)

Bardes, D'Ellen (1986). Implications of CD-Interactive: Direction, Specifications, and Standards. Optical Information Systems, 6(4), 324-28. (EJ342875)

Looks at proposed standard for CD-I (compact disc-interactive) and its implications for product and market development, CD-ROM, and optical publishing. Possible roles of OS9 (Microware's operating system), Polaroid's Colorcatcher, and products shown at the Microsoft CD-ROM conference in the development of the CD-I market are discussed. (Author)

Barker, Philip (1986). Video Discs in Education. Education and Computing, 2(3), 193-206. (EJ355785)

This discussion of the use of images in learning processes focuses on recent developments in optical storage disc technology, particularly compact disc-read only (CD-ROM) and optical video discs. Interactive video systems and user interfaces are described, and applications in education and industry in the United Kingdom are reviewed. (Author/LRW)

Barlow, Diane \& others. (1987). CD-ROM in a High School Library Media Center. School Library Journal, 34(3), pp66-68, 70-72. (EJ361416) 
Describes the experiences of high school students using microcomputers to access an electronic version of an encyclopedia in the school's media center. The topics discussed include hardware and software requirements of the CD-ROM format, information seeking strategies and problems observed, student satisfaction with the system, and recommendations for similar projects. (CLB)

Becker, Karen A. (1987). CD-ROM: A Primer. College and Research Libraries News, 48(7) p38890, 392-93. (EJ357076)

Presents a "family tree" of optical technologies with a list of definitions, and briefly discusses some of the issues relating to optical technologies and their use in libraries. (CLB)

Beiser, Karl (1986). Microcomputing. Wilson Library Bulletin, 60(8), 42-43. (EJ334686) Describes a product - BiblioFile, Library Corporation's catalog production system - and a service - reproduction of public domain software on CD-ROM for sale to those interested which revolve around the ultra-high density storage capacity of CD-ROM discs. Criteria for selecting microcomputers are briefly reviewed. (MBR)

Bezanson, Deborah (1987). Integrating CD-ROM with Printed and Online Services: A Silver Platter End-User Perspective. Optical Information Systems, 7(6), 387-90. (EJ365042)

Discusses the George Washington University Library's experiences as a test site for Silver Platter/Psychlit. Advantages of the CD-ROM concept, including visibility, accessibility, costs, and sophistication, are noted; crucial issues in deciding whether to acquire a CDROM product are considered; and CD-ROM is described as a means for integrating print and online sources. (MES)

Bills, Linda G. \& Helgerson, Linda W. (1988). User Interfaces for CD-ROM PACs. Library Hi Tech, 6(2), 73-115. (EJ375227)

Compares features of user interfaces for CD-ROM public access catalogs by six vendors: (1) Auto-Graphics; (2) Brodart; (3) General Research Corp.; (4) Library Corporation; (5) Library Systems and Services, Inc.; and (6) Marcive. Brief evaluations of the products are included, and detailed descriptions of each are appended. (MES)

Bills, Linda G. \& Helgerson, Linda W. (1988). CD-ROM Public Access Catalogs: Database Creation and Maintenance. Library Hi Tech, 6(1), 67-86. (EJ372367)

Reports information gathered from eight vendors on the preparation of bibliographic data for CD-ROM public access catalogs: (1) sources of bibliographic records; (2) duplicate record handling; (3) holdings and location information; (4) maintaining the database; (5) authority control; (6) record corrections; (7) extraction of subsets; (8) statistics on the databases; and (9) database uses. (MES)

Bovey, J. D. \& Brown, P. J. (1987). Interactive Document Display and Its Use in Information Retrieval. Journal of Documentation, 43(2), 125-37. (EJ357028)

Describes software for displaying documents on computer graphics screens which provide the opportunity for interactive user interfaces. Based on a software system called Guide, this new approach relies on advances in hardware, such as the CD-ROM, and can be used in the front end of a document retrieval system. (Author/LRW)

Brandhorst, Ted (1986). Distributing the ERIC Database on SilverPlatter Compact Disc - A Brief Case History. Paper presented at the ONLINE '86 Conference (Chicago, IL, November 5, 1986). (ED277394)

This description of the development of the Education Resources Information Center (ERIC) compact disc by two companies, SilverPlatter and ORI, Inc., provides background information on ERIC and the ERIC database, discusses reasons for choosing to put the ERIC database on compact discs, and describes the formulation of an ERIC CD-ROM team as part of the development process. A review of steps along the way in the development of a CD-ROM version of the ERIC database includes discussions of agreements and contracts; division of labor; marketing information/surveys; product design; conversion/ inversion specifications; retrieval system capabilities; alpha test sites; news releases, flyers, letters, status reports, and order forms, publicity (articles, conference exhibits, advertising); and documentation and user manuals. The following information is 
appended: (1) ORI/SilverPlatter Division of Responsibility; (2) ERIC Database Conversion/Inversion Specifications; (3) Search Features - Comparison of ERIC on SilverPlatter with DIALOG 2; (4) Projected Retrieval System Improvements; (5) SilverPlatter order form and subscription agreement; (6) SilverPlatter pricing information; (7) Resources in Education (RIE) Sample Record; (8) listing of ERIC Clearinghouses; and

(9) ERIC Fact Sheet. (KM)

Brandhorst, Ted (1987). Distributing the ERIC Database on Compact Disc: A Case History of Private Sector Involvement in the Distribution of Public Sector Data. Government Publications Review, 14, 541-57. (EJ361296)

Describes the partnership between the public and private sectors in developing and marketing the ERIC database in CD-ROM format. Particular emphasis is given to the marketing research and protocols of partnership that were developed. (Author/CLB)

Bristow, Ann (1988). Reference Sources on CD-ROM at Indiana University. Electronic Library, 6(1), 24-29. (EJ373750)

Describes the use of several CD-ROM products to provide access to reference sources in a large academic research library. Equipment and staffing problems and solutions, user reaction, and the impact of optical technologies on the library's fee-based searching service and planning for the future are discussed. (3 references) (Author/CLB)

Brito, Claudio J. (1987). Pan-American Health Organization CD-ROM Pilot Project. Information Development, 3(4), 208-13. (EJ362637)

Examines the difficulties faced by the implementors of information dissemination systems in developing nations and explores the possible use of optical data disk technologies to overcome them. A pilot project of the Pan American Health Organization for the production of a CD-ROM containing bibliographic references on public health is described. (Author/CLB)

Chen, Ching-chih (1985). Micro-Based Optical Videodisc Applications. Microcomputers for Information Management: An International Journal for Library and Information Services, 2(4), 217-40. (EJ334717)

This overview of optical videodisc technology focuses on microcomputer-based applications for information processing. Topics discussed include fundamentals of videodisc technology, interactive videodisc technology, and associated hardware systems; government-supported and commercial videodisc and CD-ROM information projects; and speculations on future developments. Information-related videodisc and CD-ROM products are listed. (Author/MBR)

Cribbs, Margaret A. (1987). The Invisible Drip...How Data Seeps Away in Various Ways. Online, 11(2), pp15-16, 18-26. (EJ351160)

Discusses the preservation of electronically produced data focusing on the passive destruction of data due to lack of proper care in information storage. Three case studies are presented: two involve specific media - magnetic tape and CD-ROM (compact diskread only memory) - and one the transfer of data from one system to another. (EM)

De Bloois, Michael (1987). Anticipating Compact Disc-Interactive (CD-I): Ten Guidelines for Prospective Authors. Educational Technology, 27(4), 25-27. (EJ359643)

Describes a number of different frames of reference through which educators can look at the opportunity presented by compact disc interactive (CD-I) technology, and proposes general guidelines to help them begin thinking about a more creative role as prospective authors of CD-I materials. (MES)

Demmon Berger, Debbie \& Hill, T.-Susan (1985). Schools and Technology: New and the Future. National School Boards Association, Alexandria, VA. Educational Policies Service Updating School Board Policies, 16(11), 1-3, Dec. (ED264658)

School systems, by and large, are hesitating in integrating new technology into the educational process. The new technology includes computers, telecommunications, 
electronic blackboards, interactive video for simulations, editing devices, and the new optical storage disk, the CD/ROM. Many believe the new technology can help to address such concerns as diverse population needs, equity in education, uniformity in curriculum, the shortage of qualified teaching personnel, and the need for lifelong learning and retraining experiences. School boards involved in the purchase of new technology are advised to begin with a planning committee - involving teachers - for long-range planning and to formulate a district needs assessment. Policy statements need to be made concerning equipment purchasing, ownership, use, and maintenance. Since most school systems will not have the resources for immediate, full-scale computerization, priorities must be set. Planners can move from a generalized statement to more specific curriculum, hardware, software, and staff development needs. (MLF)

Demo, William (1986). The Idea of "Information Literacy" in the Age of High-Tech. (ED282537)

The Information Age is being driven by an acceleration of technological breakthroughs including microcomputers, cable television, electronic publishing, fiber optics, satellite communications videotext, online database searching, high density CD-ROM storage, and robotics. A new intellectual skill that will enable us to be masters of new communications and information technologies is needed. This skill - which is called information literacy has been written about from a number of different perspectives by information industry spokespersons, librarians, educators, and communications researchers. Some

characteristics of information technology might actually be impediments to the attainment of information literacy for many: (1) generation of an over supply of information; (2) cost of information machines; (3) cost of information access; (4) invisibility of the information revolution to the average person; and (5) the "de massification" of mass media. Libraries in secondary and higher education often provide the needed focus for information literacy programs. The public library can provide similar programs for the general population; however, underuse and underfinancing may hinder such efforts. It is necessary to make the components of the online information environment more visible and accessible to potential users - those who are pre-information literate. Not to do so in an active, concerted manner will mean that information needs for significant parts of the population will remain unidentified, unexpressed, and unmet. Twenty-five references are listed. (MES)

Desmarais, Norman (1986). Buying and Selling Laserbases. Electronic and Optical Publishing Review, 6(4), 184-88. (EJ349678)

Discusses factors that should be considered by buyers and producers of databases on CDROM (compact disc-read only memory). The advantages and disadvantages of CD-ROM are also discussed and compared with those of magnetic and print media, and market projections are provided. (CLB)

Desmarais, Norman (1987). Information Management on a Compact Silver Disc. Optical Information Systems, 7(3), 193-204. (EJ367792)

Describes CD-ROM applications in the following areas: (1) reference services; (2) indexes and abstracts; (3) business; (4) medicine; (5) law; (6) education; and (7) map and geographic information. A 58-item company and product directory is included. (MES)

Duggan, Mary Kay (1987). A Look at Dialog's First CD-ROM Product. Optical Information Systems, 7(6), 401-05. (EJ365043)

Discusses reasons for selecting ERIC with the Dialog OnDisc software for training information professionals in online searching at the University of California, Berkeley, and analyzes some of the features of the CD-ROM software. Pros and cons of online and OnDisc access are summarized, and three references are listed. (Author/MES)

Dunman, Susan (1988). ERIC: An Essential Online Tool for Educators. Electronic Learning, 7(4),45-47. (EJ363828)

Describes the Educational Resources Information Center (ERIC), a national information network in the field of education. Printed indexes are explained as well as online 
searching of the ERIC database. Online searching is emphasized, including search strategies, database vendors, cost considerations, gateway services, and CD-ROM versions. (LRW)

Epler, Doris M. \& Cassel, Richard E. (1987). ACCESS PENNSYLVANIA: A CD-ROM Database Project. Library Hi Tech, 5(3), 81-92. (EJ362626)

Describes ACCESS PENNSYLVANIA, a statewide program structured around school libraries which has two objectives: (1) production of a union catalog to facilitate resource identification and retrieval, and (2) development of automated support capabilities within the libraries served by the project. The CD-ROM microcomputer technology used, Le Pac, is described by Virginia Gatcheff. (MES)

Evans, John \& Park, Betsy (1987). Information Retrieval Center: A Proposal for the Implementation of CD-ROM Database Technology at Memphis State University Libraries.(ED289520)

This planning proposal recommends that Memphis State University Libraries make information on CD-ROM (compact disc-read only memory) available in the Reference Department by establishing an Information Retrieval Center (IRC). Following a brief introduction and statement of purpose, the library's databases, users, staffing, facilities, and equipment are discussed; three recommendations for the installation of CD-ROM stations are presented; and eight CD-ROM-format databases recommended for acquisition during the initial phase of IRC implementation are described, including annual subscription costs. Presented next are a consideration of database selection and workstation allocation which includes a table depicting workstation allocation and use, and a tabular presentation of workstation configurations which covers the quantity, description, and cost of workstation equipment, modems, furniture, and electrical power control equipment. Finally, site preparation specifications are presented for walls, electrical power, lighting, HVAC (heating, ventilating, and air conditioning), library computer system data cables, and telephone service. An illustration of a microcomputer power source and a library floor plan are included, and a 60-item bibliography is provided. (Author/KM)

Fitzwater, Diana \& Fradkin, Bernard (1988). CD-ROM + Fax + Shared Reference Resources. American Libraries, 19(5), p385. (EJ373754)

Describes the Reference by GammaFax Project, which joined nine area libraries to provide cooperative reference access to optical disk databases. The configuration of disk players, microcomputers, and facsimile equipment used by the libraries is explained, and the improvements in cost effectiveness, provision of service, and librarian expertise are discussed. (CLB)

Forecast: Ten Trends for CD-ROM and OROM. (1986). TechTrends, 31(3), 17 Apr. (EJ336285) Rothchild Consultants, a market research and publishing firm, predicts how the market for optical disc-read only memory (OD-ROM) products will evolve. (MBR)

Glitz, Beryl (1988). Testing the New Technology: MEDLINE on CD-ROM in an Academic Health Sciences Library. Special Libraries, 79(1), p28-33. (EJ365091)

Describes the experiences of the University of Southern California at Los Angeles (UCLA) Biomedical Library in testing MEDLINE on CD-ROM. Preparations for testing are discussed, as well as patron response to the system, measured by evaluation forms, and implications for libraries providing new technological tools for patrons. (MES)

Glossary of CD-ROM-Related Technical Terms and Acronyms. (1986). Optical Information Systems, 6(3), 230-34. (EJ339171)

Defines approximately 95 of the most important and widely used industry terms, phrases, acronyms, and concepts for individuals new to compact disc-read only memory (CDROM) technology. (MBR)

Goodwin, Bryan \& Schroeder, Paul (1987). Guide to Sources: Using ERIC on Dialog's On Disc. Maine Univ., Orono, Raymond H. Fogler Library. (ED291407) 
This user's guide to conducting a preliminary search of the ERIC (Educational Resources Information Center) database on CD-ROM (Compact Disk-Read Only Memory) begins by briefly describing the types of materials found in ERIC and explains the four steps common to any computer search: (1) definition of topic elements and formation of concept groups of related terms; (2) gathering of terms of one concept group into a basic set of records; (3) modification of this set by adding new groups of related terms; and (4) display and printing of results. Computer commands and instructions for each of these steps are provided to reinforce the menus that appear on the screen during a search. Other useful commands are also briefly described, and students who wish more thorough searches of ERIC and/or access to information in other areas are advised to speak with the reference librarians. (CGD)

Graves, Gail T. \& others. (1987). Planning for CD-ROM in the Reference Department. College and Research Libraries News, 48(7), pp393, 395-96, 399-400. (EJ357077)

Outlines the evaluation criteria used by the reference department at the Williams Library at the University of Mississippi in selecting databases and hardware used in CD-ROM workstations. The factors discussed include database coverage, costs, and security. (CLB)

Hagan, Dalia L. (1987). The Tacoma Debut of Books in Print Plus. Library Journal, 112(14), 14951. (EJ359660)

Describes the Tacoma Public Library's experience with "BIP Plus," the CD-ROM version of Books in Print. Memory requirements, search capabilities, automatic ordering, and the library staff's response are discussed. Keyword searching is explained as the system's most used feature, and price the area of most serious concern. (EM)

Harrison, Nancy \& Murphy, Brower (1987). Multisensory Public Access Catalogs on CDROM. Library Hi Tech, 5(3), 77-80. (EJ362625)

BiblioFile Intelligent Catalog is a CD-ROM based public access catalog system which incorporates graphics and sound to provide a multisensory interface and artificial intelligence techniques to increase search precision. The system can be updated frequently and inexpensively by linking hard disk drives to CD-ROM optical drives. (MES)

Harvey, Francis A. (1987). Emerging Digital Optical Disc Technologies: An Opportunity and a Challenge for Educational Researchers. AECT RTD Newsletter, 12(1), 2-10. (EJ361351) Description of new applications of digital optical disc storage technologies focuses on CDROM (Compact Disc-Read Only Memory); CD-I (Compact Disc-Interactive); and DV-I (Digital Video-Interactive). Features of each technology are described in the context of instructional design and educational technology, and the role of educational research in their development is discussed. (LRW)

Harvey, Francis A. (1988). Applications of Artificial Intelligence to Information Search and Retrieval: The Development and Testing of an Intelligent Technical Information System. In Proceedings of Selected Research Papers presented at the Annual Meeting of the Association for Educational Communications and Technology (New Orleans, LA, January 14-19, 1988). (ED295644)

This paper describes the evolution and development of an intelligent information system, i.e., a knowledge base for steel structures being undertaken as part of the Technical Information Center for Steel Structures at Lehigh University's Center of Advanced Technology for Large Structural Systems (ATLSS). The initial development of the Technical Information Center is discussed, and the decisions on hardware and software made in the first year are reviewed. In particular, the factors instrumental in the selection of Turbo Prolog as the programming language are detailed. The computer-based bibliographic database designed during the first year of the project and now under development is described, and lessons from the experience and their impact on the future direction of the project are discussed. Projected future activities - including testing of the bibliographic system, expansion of that system into a complete knowledge based system, and conversion of the system to an optical disc (CD-ROM) storage format - and potential research questions associated with developing and using intelligent information systems are also discussed. (EW) 
Helgerson, Linda W. (1986). CD-ROM Search and Retrieval Software: The Requirements and Realities. Library Hi Tech, 4(2), 69-77. (EJ342789)

Discusses search and retrieval software for use with CD-ROM. Background trends, how data are made usable, supply and demand, data preparation services, and capabilities of search software are described. Vendors of significant information retrieval products are identified, and the characteristics of 12 packages are compared. (Author/EM)

Helgerson, Linda W. (1987). Acquiring a CD-ROM Public Access Catalog System. Part 1: The Bottom Line May Not Be the Top Priority. Library Hi Tech, 5(3), 49-75. (EJ362624)

Compares pricing of seven CD-ROM-based public access catalog systems for libraries of diverse sizes and groupings. Other features of the systems are outlined in the broad areas of database preparation, indexing, database updates, hardware, information retrieval, library controlled elements, interlibrary loan, reports, user support, future developments, and current installations. (MES)

Herther, Nancy K (1985). CD-ROM Technology: A New Era for Information Storage and Retrieval? Online, 9(6), 17-28. (EJ325582)

Introduction to use of compact disk technology for storing digital data highlights history, background, and developments, technical features; standardization issues; current $\mathrm{CD}$ ROM applications; and the market for CD products. A production diagram, a sampling of $\mathrm{CD}$ manufacturers and disk replicators, and performance comparison of three storage media are included. (E]S)

Herther, Nancy K. (1987). CD-ROM and Information Dissemination: An Update. Online, 11(2), 56-64. (EJ351162)

This current overview of optical disk technology describes the evolving marketplace for optical products, the use of libraries as test sites for prototype CD-ROM (compact diskread only memory) products, CD-ROM developments, new optical technologies, and advances in magnetics. A list of some compact disk manufacturers and a glossary of terms are included. (EM)

Hlava, Marjorie M. K. \& others. (1987). CD-ROM vs. Online. Bulletin of the American Society for Information Science, 14(1), 14-27. (EJ361328)

This series of ten articles exploring users' reactions to optical data disk technologies, focuses on comparisons with online retrieval systems. The opinions of users and vendors on cost effectiveness, searchability, equipment requirements and performance, effectiveness, and efficiency are presented and discussed. (CLB)

Huffman, Robert F. (1987). In Praise of Mr. S. Platter and His Marvelous, Magnificent CDROM Laser Disc Index for ERIC and PSYCHLIT. (ED284579)

These instructions are designed to help patrons of the University of Missouri - Columbia library perform searches on PSYCHLIT, a CD-ROM (compact disc-read only memory) version of the Psych Abstracts database, and a CD-ROM version of the ERIC database, both produced by SilverPlatter Information Services. Basic information is provided about the disk contents, use of the work station function keys, viewing and evaluating records, and printing search results. In addition, a four-part set of instructions, "How to Do a Search on the ERIC/PSYCHLIT CD-ROM indexes," provides the following information: (1) instructions for performing a practice search using prescribed terms, displaying the retrieved records, and printing the search results; (2) instructions to enable a user to perform a search on a topic of his or her choice and to display and print the results; (3) helpful hints for completing a successful search; and (4) questions and answers about searching. A checklist of 22 items that a patron-trainee should be made aware of in order to use the ERIC and PSYCHLIT CD-ROM indexes and four suggestions for the librariantrainer is also included. (KM)

Imhiff, Kathleen \& others. (1987). Putting Technology in Its Place. Public Libraries, 26(4), 14550. (EJ363779)

Three currently available technologies - telefacsimile, gateway software, and CD-ROM - 
are defined, and factors to be considered in selecting these technologies for use in public libraries are listed. Seven references are included. (MES)

Kahn, Paul (1987). Isocrates Project. Final Report. IRIS Technical Report 87-2. CS: Brown Univ., Providence, RI. Inst. for Research in Information and Scholarship. (ED296736)

A project at Brown University has developed a set of application and system software that provides access to a database of Classical Greek literature which is stored on a CD-ROM. Information on the origins of the project is provided and the technical development of the system is described in detail, including the creation of Classical Greek fonts, indexing the texts, creating the CD-ROM, developing a device driver for the CD-ROM player, adding support for a compact disk file system, and the creation of a menu interface. The delivery of the system to the Classics and Religious Studies department at Brown is then described, along with a summary of the uses of the system in each department. The progress of the system thus far is evaluated, and some suggestions for further development are made. The text is supplemented by 12 figures. (15 bibliographic notes/references) (Author/EW)

Kennedy, H.-Edward (1986). Information Delivery Options over Three Decades. NFAIS Newsletter, 28(2), 31-47 Apr. Miles Conrad Lecture presented at the Annual Conference of the National Federation of Abstracting and Information Services (28th, Philadelphia, PA March 2-5, 1986). (ED274365)

The rate of new technology-driven innovations for information delivery has accelerated over the past three decades. New information delivery formats in the 1950s and 1960s included microforms and, in response to demands from librarians, indexing and abstracting services began to make their publications available on this medium. Electronic processing and delivery of machine readable records became a reality in the late 1960s; magnetic tapes were developed, and online distribution followed. Online usage on a broad scale occurred much more quickly than predicted, first as bibliographic entries, then as abstracts, and finally full-text formats became available online. Recent information delivery mechanisms and issues include floppy discs, downloading, vertical integration, value added, electronic publishing, optical discs, and CD-ROM. These technological applications have had a vast impact not only on the way information is processed and delivered to its point of use, but also on how it is used. During the decade ahead, the need for carefully weighed decisions will be greater than ever. Material pertinent to this topic is listed in an accompanying 34 item bibliography. (Author/KM)

Kuhlman, James R. \& Lee, Everett S. (1986). Data - Power to the People. American Libraries, 17(10), pp 757-58, 760, 778. (EJ344300)

The development of CD-ROM following early computers and powerful personal computers will affect information retrieval by its accessibility and large storage capacity. Users will demand specific information and data sets from libraries, which could provide large research capacities. Librarians will act as database managers, thus enhancing their roles. (CDD)

Kuhn, Carolyn (1987). Questions and Answers about CD-ROM. CALICO Journal, 5(1), 73-76. (EJ370551)

Question and answer column about the CD-ROM medium discusses: (1) optical storage devices available; (2) language teaching applications; (3) types of courseware available; (4) costs to hook up a CD-ROM drive as a peripheral to an existing system; (5) how to go about developing and mastering a disk; and (6) mastering and replication costs. (Author/LMO)

Lambert, Steve \& Ropiequet, Suzanne, (Eds) (1986). CD-ROM. The New Papyrus: The Current and Future State of the Art. ISBN-0-914845-74-8. Microsoft Press, 16011 NE 36th, Box 97017, Redmond, WA 98073-9717 (ED273263)

This compendium of 44 articles written by leading authorities provides an in-depth and instructive overview of CD-ROM (Compact Disk-Read Only Memory) for both the professional and the newcomer to the field. Three articles serve as an introduction to the book: (1) "As We May Think," Vannevar Bush; (2) "Finally It Works - Now It Must 'Play in 
Peoria,"' David C. Miller; and (3) "CD-ROM and Videodisc: Lessons To Be Learned," Rockley L. Miller. The next section provides an overview of CD-ROM technology via articles on the hardware, system software, and retrieval software. The third section focuses on production techniques, including data preparation, data indexing, image capture and processing, and compressing and digitizing images. Section 4 considers the elements of design as it relates to the human factor, authoring and development, and project management. CD-ROM publishing is discussed in Section 5, and the applications described in Section 6 include market considerations, CD-ROM in libraries, medical and legal applications, geographic applications, and archive and research applications. Additional resources listed in Section 7 include persons who contributed to the book either by writing an article or by answering questions and giving advice, and companies and individuals contacted during the compilation of the book. An index is provided.

LaRue, James (1988). The Electronic Hermit: Trends in Library automation. Wilson Library Bulletin, 62(6), pp 24, 26, 28, 30, 109. (EJ367789)

Reviews trends in library software development including: (1) microcomputer applications; (2) CD-ROM; (3) desktop publishing; (4) public access microcomputers; (5) artificial intelligence; (6) mainframes and minicomputers; and (7) automated catalogs. (MES)

Laser Disk Systems in Libraries. (1987). Summary of Proceedings of FLICC/FEDLINK Institute (Washington, D.C., May 11, 1987). Federal Library and Information Center Committee, Washington, DC. (ED291386)

This document summarizes the nine presentations made at an institute on laser disk systems in libraries held at the Library of Congress in May 1987. The first speaker, Linda Helgerson, discussed advances in CD-ROM technology as well as its advantages and disadvantages. Judy McQueen focused primarily on the disadvantages of CD-ROM and urged caution in adopting the new technology. Deborah Bezanson described the implementation and evaluation of patron access to the PsychLit database on CD-ROM in an academic library. Less satisfactory experiences with the use of INFOTRAC by law students and law professionals who had experience with online searching were described by Phil Berwick. Experiences with Books-In-Print Plus (BIP+) were related by Chester Pletzke, who was favorably impressed by the system but found that listings for publishers were not up-to-date. Charles Worsley discussed applications of CD-ROM in school libraries and outlined plans for implementing CD-ROM in a public school district. The costs of CD-ROM systems and problems in dealing with vendors and consultants were discussed by Charles Robinson. Linda Kosmin observed that most producers have been slow to recognize the market potential of scientific and technical libraries for the right products. The final speaker, Michael Halperin, described the advantages of DATEXT as a source of data on individual companies and industries. A list of exhibitors at the institute concludes the report. (CGD)

Lehrer, Ariella (1988). A Network Primer: How They're Used... and How They Could Be Used. Classroom Computer Learning, 8(7), pp 41-42, 44-48. (EJ371083)

Examined are large curriculum software packages that currently dominate school networks. Indicates ways that networks could serve schools. Discusses different Integrated Learning Systems (ILS), evaluates their use and proposes future uses of these networks. (CW)

Lunin, Lois F, \& Schipma, Peter B. (Eds) (1988). Perspectives in CD-ROM for Information Storage and Retrieval. Journal of the American Society for Information Science, 39(1), 30-66. (EJ365080)

A series of six articles discusses the technology of optical data disks, current and possible future applications of this technology, their potential impact on information retrieval systems, and the potential problems as they apply to information science. (CLB)

McGinty, Tony (1987). Three Trailblazing Technologies for Schools. Electronic Learning, 7(1), 26-30. (EJ358365) 
Provides an overview of the capabilities and potential educational applications of CDROM (compact disk-read only memory), artificial intelligence, and speech technology. Highlights include reference materials on CD-ROM; current developments in CD-I (compact disk interactive); synthesized and digital speech for microcomputers, including specific products; and artificial intelligence products for educators. (RP)

McLaughlin, Pamela (1987). CD-ROM for Educators. ERIC Digest. ERIC Clearinghouse on Information Resources, Syracuse, N.Y. (ED290463)

This overview of CD-ROM (Compact Disk-Read Only Memory) technology covers technical specifications as well as applications of special interest to teachers, school administrators, and librarians. Materials available on CD-ROM disks are described, including a variety of reference works, and a directory of publishers/ producers is provided. Issues of concern and trends are also briefly discussed, including new technologies that will permit the local addition of data and networking. A nine item bibliography is provided. (EW)

McLaughlin, Pamela W. (1987). New Access Points to ERIC-CD-ROM Versions. ERIC Digest. ERIC Clearinghouse on Information Resources, Syracuse, N.Y. (ED283533)

This digest reviews three CD-ROM (compact disc-read only memory) versions of the ERIC (Educational Resources Information Center) database currently being delivered or tested and provides information for comparison. However, no attempt is made to recommend any one product. The advantages and disadvantages of the acquisition of $\mathrm{CD}$ ROM databases are discussed, and the vendor address as well as a description of the database scope and information on software capabilities, hardware requirements, and any notable features are provided for the following products: (1) DIALOG OnDisc ERIC, produced by DIALOG Information Services, Inc.; (2) OCLC Search CD450 for Education, produced by the Online Computer Library Center; and (3) SilverPlatter ERIC, produced by SilverPlatter Information, Inc. In addition, a table presents a comparison of the current disc contents, archival disc contents, hardware, $\mathrm{CD}$ drives, and prices of the three products. (KM)

Micco, Mary \& Smith, Irma (1987). Designing an Integrated System of Databases: A Workstation for Information Seekers. Library Software Review, 6(5), 259-62. (EJ362676) Proposes a framework for the design of a full function workstation for information retrieval based on study of information seeking behavior. A large amount of local storage of the CD-ROM jukebox variety and full networking capability to both local and external databases are identified as requirements of the prototype. (MES)

Miller, David C. (1986). Laser Disks at the Library Door: The Microsoft First International Conference on CD-ROM. Library Hi Tech, 4(2), 55-68. (EJ342788)

Description of First International CD-ROM Conference held by Microsoft, Inc., in March, 1986, covers types of participants, hardware and support services, and technical standards and intellectual property rights as market barriers. The importance of librarians planning for CD-ROM is stressed, and a detailed directory of references and contacts is included. (EM)

Miller, David C. (1986). Running with CD-ROM. American Libraries, 17(10), 754-56. (EJ344299) An information industry analyst suggests ways for librarians to deal with the acquisition and use of CD-ROM technology in their libraries. Practical information is provided on needs assessment, purchasing, system standards, and user access and fees, as well as sources of optical disk systems and titles. (CDD)

Miller, Tim (1987). Early User Reaction to CD-ROM and Video-Based Optical Information Products in the Library Market. Optical Information Systems, 7(3), 205-09. (EJ367793) Summarizes early-user response from several academic and special libraries to CD-ROM information products, including (1) promotion; (2) training; (3) user reaction; (4) impact on online and print usage; and (5) costs and other barriers. Caution is advised in interpreting these responses. A list of the 11 sources for the survey is included. (MES) 
Moes, Robert J. (1986). The CD-ROM Puzzle: Where Do the Pieces Fit? Optical Information Systems, 6(6), 509-11. (EJ347598)

Representing the point of view of Philips Subsystems and Peripherals on Compact DiscRead Only Memory (CD-ROM) and Compact Disc-lnteractive (CD-I) issues, this position paper attempts to point out differences and similarities between the basic CD-ROM standard and the CD-I standard proposed for interactive use of data. (Author/MBR)

Morrison, James W. (1986). Role of Colleges in the Coming Demise of the Personal Computer Industry. Paper presented at a Conference of NERCOMP (New England Regional Computer Programs) (Hanover, NH, January 18, 1986). (ED273257)

The concept of the personal computer (PC) as a stand-alone, single-user computer has had its day. The 8-bit processors cannot support the newer applications, and, although there have been some advances in 16-bit microprocessors, the "second generation" software is immature and does not work well. The immediate problem for colleges and universities is how to replace and/or upgrade their obsolete computing equipment. The trend is toward 32-bit PCs and connecting, sharing databases, and linking departments. The "age of the peripherals" is beginning, and add-ons will include 640K RAM, enhanced graphic boards, laser printers, local area networks, high-resolution graphics monitors, fixed disks, hard disk boards, and CD-ROM players. Future enhancements to existing PC DOS operating systems will incorporate multi-tasking, which will allow users to run a variety of applications simultaneously. The evolution from 16-bit to 32-bit technology will enable users to protect their investment in hardware and software, and software will take full advantage of increased memory, storage, and multi-tasking capabilities. The PC of the future will have to be a strategic education tool for learning. It must be able to program major languages; be capable of accessing library databases; be a remote, online tutorial unit; be able to download instructional databases to fixed disk storage or a CD-ROM device; be a terminal for electronic mail, class assignments, and campus news; be an efficient word processor with a full keyboard; and have graphics-based software and sound/voice capabilities. Advanced versions of the laptop computer will be especially important for student use. (DJR)

Nelson, Nancy \& others. (1987). CD-ROM Comes of Age. Wilson Library Bulletin, 62(4), pp 1922, 24-26, 28-30, 32-34, 36-38, 41-42, 102. (EJ363798)

This special issue on CD-ROM composes six articles covering the following topics: (1) an overview of the library market; (2) the producer's perspective; (3) implementation issues; (4) problems; (5) future needs and trends; and (6) a 23-item bibliography which includes an annotated section designed as a self instructional module. (MES)

Nitecki, Danuta A. (Ed.) (1986). Energies for Transition. Proceedings of the National Conference of the Association of College and Research Libraries (4th, Baltimore, Maryland, April 9-12, 1986). (ED294589)

This proceedings of the 1986 conference of the Association of College and Research Libraries contains 60 papers - 44 position papers, 7 research reports, and 9 idea briefs dealing with the issue of transitions facing librarians and ways to respond to these transitions through both formal and informal means. Papers are organized under eight broad topics: (1) academic and research librarianship; (2) bibliographic control; (3) bibliographic instruction; (4) collections management; (5) library administration; (6) personnel; (7) reader services; and (8) technology. Specific topics addressed in the refereed collection of papers include: "The Plateaued Employee and the Manager's Role" (James F. Comes); "Financing Academic Libraries" (John M. Cooper); "Developing-World Imprints in Academic Library Collections" (David L. Easterbrook); "Psychological Needs and Source Linkages in Undergraduate Information-Seeking Behavior" (Kathleen Dunn); "CDROM Optical Disk Technology in Libraries" (Nancy L. Eaton and Julie B. Schwerin); "Academic Library Censorship in a Conservative Era" (Elizabeth Hood); "A Populist Approach to Automation: Developing Local Systems in a Mainframe Context" (David F. Kohl); "Capturing the Mainstream: An Examination of Publisher-Based and Subject-Based Approval Plans in Academic Libraries" (Karen A. Schmidt and Robert G. Sewell); and "Technical Services: Public Services behind Closed Doors" by Georgene A. Timko. A directory of contributors and author and subject indexes are included. (MES) 
O'Connor, Mary Ann (1986). Education and CD-ROM. Optical Information Systems, 6(4), 32931. (EJ342876)

Discusses role of CD-ROM (compact disk-read only memory) as a catalyst bringing together libraries, publishers, technology companies, and education in the development of creative solutions to educational problems. CD-ROM applications in the educational environment, specific efforts by libraries, and product development by publishers and technology companies are reviewed. (MBR)

Olson, Lucie (1987). Experiencing CD-ROM ERIC. Education Libraries, 12(3), 77-80. (EJ361402) Briefly describes DIALOG OnDisc and gives an example of an actual search of the ERIC database using this system. The screen displays and search commands are used to illustrate the differences between the easy menu search method provided for novice users and the command search method provided for experienced users. (CLB)

Paisley, William \& Butler, Matilda (1987). The First Wave: CD-ROM Adoption in Offices and Libraries. Microcomputers for Information Management: An International Journal for Library and Information Services, 4(2),109-27. (EJ358339)

Predictions for the future of optical disk technology are based on three phases of development: feasibility testing; use as a replacement technology for older technologies; and the introduction of new applications not possible in older technologies.

(Author/CLB)

Paisley, William \& Butler, Matilda (1988). The First Wave: CD-ROM Adoption in Offices and Libraries: I. OCLC-Micro, 4(1), 19-23. (EJ370776)

The first of two articles provides an overview of four revolutions in publishing - the movable-type printing press, mechanization, the computer, and optical disc technology. The first phases of CD-ROM development - demonstration of feasibility and testing of replacement functions - are described and compared with earlier technologies. (3 references) (MES)

Paisley, William \& Butler, Matilda (1988). The First Wave: CD-ROM Adoption in Offices and Libraries: II. OCLC-Micro, 4(2), pp 15-22, 26. (EJ370777)

The second of two articles discusses topics relating to the development of CD-ROM technology: (1) new applications; (2) the image of what CD-ROM will become; (3) the properties of information, including timeliness, risk, and the relationship between message and medium; and (4) growth issues such as production, pricing, and user training and support. (MES)

Peters, Charles (1987). Databases on CD-ROM: Comparative Factors for Purchase. Electronic Library, 5(3), 154-60. (EJ357066)

Describes databases available on optical disks, compares the databases with their print and online analogs, and suggests that the librarian should call such products to the attention of users needing information available in CD-ROM format. Five features desirable to most libraries are listed. (Author/CLB)

Plati, Thomas (1988). Using High-Tech Tools for Student Research. Media and Methods, 24(5), 29-32. (EJ373793)

Discusses incorporating high technology research tools into the curriculum for grades 5 through 12 in Shrewsbury, Massachusetts, public schools. The use of CD-ROM and online databases is described, teacher training is discussed, and steps to integrate this new technology are listed, including budget proposals and evaluation. (LRW)

Power On! New Tools for Teaching and Learning. (1988). Congress of the U S., Washington, D C. Office of Technology Assessment. Washington: U.S. Government Printing Office. (ED295677)

This report on the potential of new interactive technologies for improving learning examines developments in the use of computer-based technologies, analyzes key trends in hardware and software development, evaluates the capability of technology to improve 
learning in many areas, and explores ways to substantially increase student access to technology. The role of the teacher, teachers' needs for training, and the impact of federal support for educational technology research and development are reviewed as well. Specific topics addressed include the adoption of computer and video technologies; evaluation research; computer-assisted instruction (CAI) and intelligent CAI; mathematics and science; multimedia programs; database management; word processing; language arts; electronic networks; cost-effectiveness; software; and research and development. The future of classroom instruction is discussed in terms of networking and distance education, CD-ROM and computer/video convergence, hypermedia, integrated learning systems, and videodisks. Appended materials include a summary of state activities in educational technology; criteria used to evaluate educational software; principal programs of the U.S. Department of Education that are providing funds for technology in education; a list of acronyms; and a bibliography of contractor reports. Also included are a copy of the September 1988 OTA Report Brief entitled "Power On! New Tools for Teaching and Learning," and a September 15, 1988 Press Release announcing two videotapes on the influence and potential of educational technology in public schools, now available from St. Publications, New York.

Reese, Carol (1988). Manual Indexes versus Computer-Aided Indexes: Comparing the Readers' Guide to Periodical Literature to InfoTrac II. $R Q, 27(3), 384-89$. (EJ372388) The relative effectiveness of the CD-ROM information retrieval system, InfoTrac II, and the manual "Readers' Guide to Periodical Literature," was studied. Seventeen community college students were divided into two groups which researched the same questions either on CD-ROM or in the printed index. Results showed the "Readers' Guide" to be more effective. (6 references) (MES)

Reese, Jean (1988). A Comparison and Evaluation of Three CD-ROM Products. Optical Information Systems, 8(3), p123-26. (EJ373753)

Compares and evaluates three CD-ROM products for the ERIC database: (1) DIALOG

OnDISC; (2) OCLC's Search CD450; and (3) SilverPlatter. The focus is on search capabilities and features. (1 reference) (MES)

Remington, David Gray (1987). Rural Communities and Optical Information Technologies: Optical Disks Move Rural America Closer to the Information Mainstream. Portland, OR: Fred Meyer Charitable Trust. (ED288540)

Optical disk technologies now offer a way to move large, complex, remote computer databases from the large urban areas to rural users. Recently, the Optical Information Systems (OIS) Conference provided an opportunity to discuss the use of this new technology for a variety of innovative applications; for example, "The State Education Encyclopedia," published on CD-ROM (compact disk-read only memory) in Texas, which provides remote users with access to an enormous mix of documents in a matter of seconds. In fact, CD-ROM technology offers the opportunity to publish a variety of information of value to rural areas, including state codes of law and administrative codes; packages of guidelines and excerpts of laws, codes, regulations, and other documents; large files cataloging the holdings of libraries; indexes and catalogs that allow easy access to inventories; and maps and indexes to the features of specific local areas. Optical disk technology offers challenges for information seekers to accept new possibilities; for publishers to anticipate seekers' needs; for publishers and users to think about how information is most usefully accessed, displayed, printed out, digested, and stored for end-users; and for city and county officials, business managers, organization leaders, and individuals to carefully evaluate their current methods of storing, using, and accessing information. (KM)

Rice, James (1986). The Golden Age of Reference Service: Is It Really Over? Wilson Library Bulletin, 61(4), 17-19. (EJ347583)

Argues that reference services will not only survive changes brought about by new technologies, but will be improved and enhanced as a result. Examples given include online public access catalogs, automated record keeping operations, CD-ROM as an 
information storage medium, the continuing need for intermediaries in online searching, and copyright law. (EM)

Rodgers, Don (1986). Data Preparation for CD-ROM. Optical Information Systems, 6(3), 209-13. (EJ339169)

Explains steps in process of tranforming data from current form to one ready for publication on CD-ROM, i.e., disc layout, file format, building the master tape, and input to mastering facility. The conversion of a product currently existing in book form into a computer based searchable database is described. (MBR)

Rosen, David (1986). History in the Making: A Report from Microsoft's First International Conference on CD-ROM. Educational Technology, 26(7), 16-19. (EJ340343)

Reviews important developments of Microsoft's first international conference on CDROM, focusing on the announcement of a new medium called Compact Disc-Interactive (CD-I). Discussion covers CD-I's design, applications, kinds of programming made possible compatibility with current CD-ROM products, impact on consumer market, and impact on overall CD-ROM market. (MBR)

Sabelhaus, Linda (1988). CD-ROM Use in an Association Special Library: A Case Study. Special Libraries, 79(2), 148-51. (EJ370739)

Describes the experiences of the American Society for Training and Development library with the CD-ROM version of ERIC. The following topics are discussed: (1) installation of the CD-ROM system; (2) CD-ROM vs. online searching; (3) cost/ benefit of CD-ROM; (4) patron response; and (5) future plans. (1 reference) (MES)

Saviers, Shannon Smith (1987). Reflections on CD-ROM: Bridging the Gap between Technology and Purpose. Special Libraries, 78(4), 288-94. (EJ359771)

Provides a technological overview of CD-ROM (Compact Disc-Read Only Memory), an optically-based medium for data storage offering large storage capacity, computer-based delivery system, read-only medium, and economic mass production. CD-ROM database attributes appropriate for information delivery are also reviewed, including large database size, wide distribution, and infrequent updating. (MES)

Schneider, Edward (1987). The Magic of Optical Memories. CALICO Journal, 4(4), 83-89. (EJ370545)

Describes possible applications of optical memory developments to language education. Discusses Compact Disk-Read Only Memory and Compact Disk-Interactive, their strengths, weaknesses, targeted markets, and educational applications. (LMO)

Teasley, Tamra L. (Ed.) (1986). Finding Ways: Excellence under Pressure. Proceedings from the 1986 Spring Meeting of the Nebraska Library Association, College and University Section (Lincoln, Nebraska, May 2, 1986). (ED276458)

Based on the conference theme, "Finding Ways: Excellence under Pressure," papers presented at the 1986 meeting of the association include: (1) "Coping with Budget Pressure: A Public Services Librarian's View" (Janet C. Lu); (2) "The Librarian, the Accession List, and the Database" (B. C. Wehrman); (3) "New Start: Bibliographic Instruction for Non-Traditional Students" (Thomas A. Tollman, Laura K. Dickson, and Carol ]. Zoerb); (4) "The Philistines Are Coming, Are Coming!" (G. A. Rudolph); (5) "CDROM: What's in Store for Libraries in the Coming Year?" (Melvin M. Bohn); (6) "Turnover of Professional Librarians" (Dee Ann K. Allison); (7) "The State of Preservation and Microfilming and Its Implications" (Louis E. Jeffries); (8) "Inadvertent Personalized Reference Service" (Paul Frantz and Thomas Cashore); and (9) "On-Line Searching in Times of Retrenchment: An Informal Survey of Regional Academic Libraries" (Virginia Moreland). A brief abstract is provided for an additional presentation, "Librarians and Collective Bargaining at UNO (University of Nebraska at Omaha)" (Carole Larson, Mel Bohn, and Bob Nash). (KM) 
Vandergrift, Kay E. \& others. (1987). CD-ROM: An Emerging Technology. Part 2: Planning and Management Strategies. School Library Journal, 33(11), 22-25. (EJ358323)

Outlines the stages in the decision-making process for libraries acquiring optical data disk systems, including the establishment of a project manager or task force, feasibility studies, creating a planning document, hardware and software evaluation, devising processes and policies, and analyzing contracts. (CLB)

Vandergrift, Kay E. \& others. (1987). CD-ROM: Perspectives on an Emerging Technology. School Library Journal, 33(10), 27-31. (EJ354484)

Discusses library applications of several specific CD-ROM products, including library catalogs, book reviews, databases, encyclopedias, and interactive video programs. Such factors as cost effectiveness, ease of use, and user satisfaction are discussed, and a bibliography of books about CD-ROM is provided. (CLB)

Vanderstar, John (1987). Optical Storage. International Library Review, 19(2), 153-59. (EJ352842) Classifies and briefly describes several types of optical storage media available today read-only and write-once analog disks, read-only and write-once digital disks and erasable disks. The appropriateness of CD-ROM (compact disk-read only memory) for use in libraries of developing nations is discussed in terms of users' information needs and costs. (CLB)

Videodisc and Optical Digital Disk Technologies and Their Applications in Libraries. A Report to the Council on Library Resources. (1985) CS: Information Systems Consultants, Inc., Washington, D.C. SP: Council on Library Resources, Inc., Washington, D.C. (ED257433) This report examines the potential impact of optical media - videodiscs, compact audio discs, and optical disks, tapes, and cards in library related applications. A detailed consideration of the technology includes discussion of the underlying principles, the various forms in which the technology is marketed, production methods and costs, and the capabilities of each different medium. An introductory chapter outlines the different forms of optical media and their potential applications in libraries. Each of the remaining 11 chapters then addresses the details of one of the following technologies: videodiscs; interactive videodiscs; recording digital data on videodisc; videodisc production; compact audio discs and CD-ROM (compact disc-read only memory); videodiscs and CD-ROM as digital publishing media; optical digital discs; optical digital products; and erasable optical media. A number of video and compact audio disc projects currently being developed or investigated in library settings are examined in the appropriate chapters, including audio and video applications at Video Patsearch, the National Library of Canada, the National Library of Medicine, and the Library of Congress; digital data publishing projects at MiniMARC, Information Access Corporation, Carrollton Press, the Library Corporation, and other companies; and library applications of optical digital disk technology at the Library of Congress, the National Library of Medicine, the National Air and Space Museum, the Public Archives of Canada, and Disclosure Information Group. An appendix explains the process of converting text, graphics, and audio to digital form. (THC)

Watson, J. Allen, et al. (1986). Special Education Technologies for Young Children: Present and Future Learning Scenarios with Related Research Literature. Journal of the Division for Early Childhood, 10(3),197-208. (EJ343861)

The article surveys computer usage with young handicapped children by developing three instructional scenarios (present actual, present possible, and future). Research is reviewed on computer use with very young children, cognitive theory and microcomputer learning, and social aspects of the microcomputer experience. Trends in microcomputer, interactive videodisc, and CD-ROM technology are noted. (Author/DB)

Watson, Paula D. \& Golden, Gary A. (1987). Distributing an Online Catalog on CD-ROM...

The University of Illinois Experience. Online, 11(2), 65-74. (EJ351163)

Description of the planning of a project designed to test the feasibility of distributing a statewide union catalog database on optical disk discusses the relationship of the project's 
goals to those of statewide library development; dealing with vendors in a volatile, high technology industry; and plans for testing and evaluation. (EM)

Whelan, Errol A. \& Chan, Jeanie (1988). Computerizing a High School Library. Library Software Review, 7(1), 12-16. (EJ367828)

Describes how the Swift Current Comprehensive High School (Saskatchewan) library computerized to create an online catalog, provide access to remote databases, and acquire CD-ROM reference systems. Objectives, hardware and software selection and costs, implementation, and evaluation are discussed. Seven references are listed, and a directory of suppliers is appended. (MES)

White, Charles S. (1988). Computers in Social Studies Classrooms: ERIC Digest EDO-S088-5. ERIC Clearinghouse for Social Studies/Social Science Education, Bloomington, IN. (ED296950)

Integrating computer-based learning tools into the curriculum has been slow, and the results of actual usage have been inconclusive; however, the potential for effective instruction should increase use by teachers and students. This ERIC Digest discusses three topics: (1) computer use in the classroom; (2) what is known about the effects of computer use on teaching and learning; and (3) trends likely to develop in the use of computers. Discussion of computer software includes drills, tutorials, simulations, and databases as the most commonly used programs in classrooms. Research results of computer use are presented in terms of the effects of drills and tutorials, simulations, and databases. Five projected trends include these beliefs: (1) computers will become standard fixtures because they have proven to be useful tools; (2) the national movement towards the development of thinking skills will be supported by the use of databases; (3) software development will increase as demands are made for curriculum integration; (4) there will be increased development of interactive videos; and (5) access to data will increase through the use of modems, CD-ROM discs, and hypermedia systems. A 14-item list of references and Educational Resources information Center (ERIC) resources is included. (DJC)

Wilson, Barbara \& Hubbard, Abigail (1987). Redefining the Role of School Media Specialists... Bridging the Gap. Online, 11(6), 50-54. (EJ361361)

Discussion of the changing role of the school library/media specialists argues that skill requirements for this group should be redefined to include competency in online information retrieval techniques. Appropriate online databases available on CD-ROM and sources for training are described, and a role for academic librarians in providing training is suggested. (MES)

Working Paper for Information Processing: Volume and File Structure of CD-ROM for Information Interchange. (1987) Optical Information Systems, 7(1), 29-49. (EJ349656)

These proposed standards prepared by the CD-ROM Ad Hoc Advisory Committee (the "High Sierra Group") specify the volume and file structure of compact read-only optical discs (CD-ROM) for the interchange of information between users of information processing systems. (Author/LRW)

Please cite as: Hedberg, J. G. (1989). CD-ROM: Expanding and shrinking resource-based learning. Australian Journal of Educational Technology, 5(1), 56-75. http: / / www.ascilite.org.au/ajet/ajet5/hedberg1.html 